
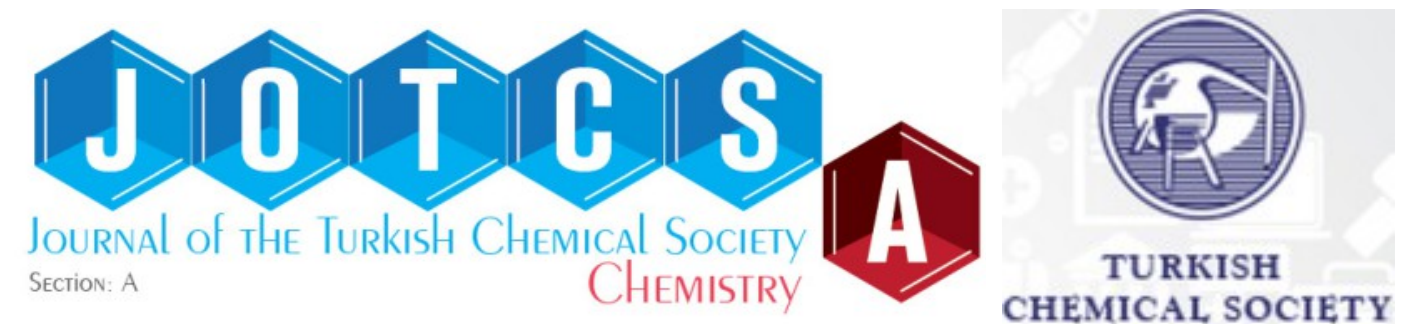

\title{
Experimental and modeling study of polyphenols in Olea europaea leaves through ultrasound-assisted extraction
}

\author{
Selin Şahin* \\ Istanbul University-Cerrahpaşa, Engineering Faculty, Department of Chemical Engineering, \\ 34320 Avcilar, Istanbul, Turkey.
}

Abstract: Olive tree (Olea europaea) leaves were extracted by ultrasound-assisted extraction (UAE). The attention was focused on the yield of extract and its polyphenols, and extraction kinetics to contribute to the application of the extraction process industrially. Samples were extracted with water, ethanol, methanol, and their aqueous solutions $(50 \%, \mathrm{v} / \mathrm{v})$ under temperature values ranging from 30 to $50{ }^{\circ} \mathrm{C}$. Additionally, the temperature interval changed between 30 and $80^{\circ} \mathrm{C}$, when water was used as the solvent. Backing the solvents with water enhanced the polyphenolic yield. Total phenolic content (TPC) from water extracts decreased after a certain temperature point, as a result of the problems of degradation. The second-order model was followed for characterizing the kinetic of the UAE process of TPC from olive leaves under various solvents and temperatures. Major phenolic component was also quantified for each solvent system by means of High Performance Liquid Chromatography (HPLC).

Keywords: Agro-industrial by-products; mathematical model; olive leaves; polyphenols extraction.

Submitted: January 04, 2019. Accepted: September 10, 2019.

Cite this: Şahin S. Experimental and modeling study of polyphenols in Olea europaea leaves through ultrasound-assisted extraction. JOTCSA. 2019;6(3):383-94.

DOI: https://doi.org/10.18596/jotcsa.508113.

"Corresponding author. E-mail: selins@istanbul.edu.tr.

\section{INTRODUCTION}

Olive tree (Olea europaea) is grown to produce table olives and olive oil, and the leaves, its abundant wastes, are traditionally used for therapeutic purposes. Olive leaf is a substantial by-product of tree pruning and fruit harvesting. Recent scientific studies have reported that phenolic extracts from all parts (such as fruit, leaves, pomace, and even olive tree extracts) of the olive crop have remarkable antioxidant activity (1-5).
Olive plantation in Mediterranean countries counts about $98 \%$ (corresponding to $8 \mathrm{ha}$ ) of the world's cultivation. Olive leaf obtained from pruning is estimated to be $25 \mathrm{~kg}$ per olive tree, accounting for approximately $10 \%$ of the total weight of the olives from the olive oil industries. So, this huge amount of waste by-product should be valorized for both economic and ecological points. Due to its beneficial effects to health, interests in this by-product have been increasing in many 
researchers and commercial organizations $(6,7)$. Generally, medical properties of this natural material is mostly attributable to oleuropein, which is its predominant phenolic ingredient $(8-10)$. Oleuropein is a phenolic secoiridoid compound, and has a formula similar to the forms of dimethyl oleuropein (sketched in ChemDraw, see Figure 1) such as ligstroside, oleuroside, and verbascoside.

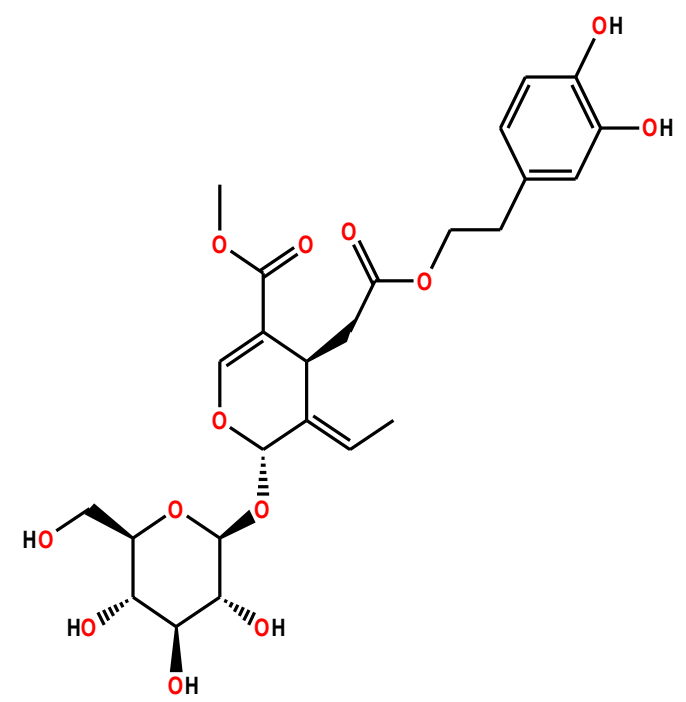

Figure 1. Molecular structure of oleuropein.

Since various biological activities of plant extracts and their phytochemical content have been reported, the study of higher plants with known ethnobotanical knowledge has attracted the attention of researchers. Due to the transition from disease-based products to products that promote healthy living, phytochemicals have high commercial value in local and global markets. In addition, the prevalence of chronic diseases that cannot be treated with conventional drugs has transformed the phytochemical industry into an approaching industrial sector. However, a common trap associated with this sector is that the production of these phytochemicals is often carried out by various conventional methods, resulting in high losses and low yields. In order to make the phytochemical industries suitable and profitable, various transformations with appropriate processes such as planting and harvesting, raw material preparation and high-added value production are required. Furthermore, the process technology for successful modernization of phytochemical processes needs to be optimized for the purpose of extraction and product formulation. In this respect, the modeling of the kinetics of a process is a beneficial engineering tool for controlling the process for industrial applications through optimization and simulation (11).

Ultrasound technology has not been developed recently (12). Sound waves having frequencies greater than $20 \mathrm{kHz}$ can move within a material and may include expansion and compression cycles during movement in the environment. The frequency between 18 and $40 \mathrm{kHz}$ range was considered to be an excellent source of energy to support ultrasound-assisted extraction (UAE). UAE is much more rapid than conventional extraction methods due to the high contact surface area between the solid matrix and liquid solvent. High frequency sound energy can separate phytochemicals from plant materials by means of cavitation. The formation and collapse of cavitation or microscopic bubbles creates a tremendous amount of energy, such as heat, pressure, and mechanical shear. Thus, it increases mass transfer and facilitates solvent diffusion to the cell $(13,14)$. In this sense, special attention has been given to the use of UAE in the recovery of bio-active compounds from diverse natural sources. The related cavitation has a great effect on extraction efficiency and its kinetics. Therefore, it enhances the penetration 
potential of the solvent to the cell matrix and favors mass transfer. In the UAE process, sonication can disturb walls of the bioactive cells by improving the release of target content. UAE is cheaper and easier to extract fine chemicals from natural raw materials comparing to other advanced methods such as microwave and supercritical $\mathrm{CO}_{2}$ (15). UAE has been suggested as an advanced separation method with better recovery of the target bioactive components with less energy and solvent consumption $(16,17)$.

In this study, olive leaves were extracted by means of UAE under several conditions. The kinetic description of the UAE process was carried out by second-order kinetic model with respect to total phenolic content (TPC) extraction. Effect of extraction temperature was also investigated as well as solvent type. Finally, the most distinguished phenolic compound of the olive leaf extract was also quantified by means of high performance liquid chromatography (HPLC).

\section{MATERIAL AND METHODS}

\section{Material}

Olive leaf samples were collected from Kaş in Mediterranean area of Turkey. Leaf samples belong to Tavşan yüreği cultivar of olives. The samples collected in November (2013), where the leaves have the highest period in terms of phenolic matter (18). The leaves were dried at ambient conditions in dark. After 4 days, the samples were stored at plastic bags kept in the dark until grinding for the extraction. The moisture of the leaf sample was nearly 16 $\%$ of the total leaf weight.
Ethanol, methanol, acetonitrile, and formic acid were purchased from Merck (Darmstadt, Germany), while Folin-Ciocalteu, gallic acid, and sodium carbonate were procured from Sigma-Aldrich (St. Louis, MO).

\section{Ultrasound-Assisted Extraction}

Extraction process was carried out in a sonicator (Protech) with $50 \mathrm{~Hz}$ of frequency under several temperature values $(30,40,50$, 60,70 , and $80^{\circ} \mathrm{C}$ ). A specific amount of leaf samples were added into the selected solvents (water, ethanol, methanol, and their $50 \%$ aqeous solutions $(\mathrm{v} / \mathrm{v})$ ), respectively. The beaker containing the material and the solvent was kept in an ice bath to maintain the temperature constant. A centrifuge (Nüve, CN 180) was used to separate the heterogeneous mixture for $15 \mathrm{~min}$ of time at $5000 \mathrm{rpm}$. Aqueous olive leaf extracts were dried in a rotary evaporator (Buchi, Switzerland) under vacuum.

\section{Folin-Ciocalteu Method}

The procedure developed by Malik and Bradford (2006) was exploited for the quantification of total polyphenolic content of the extract samples (19). UVspectrophotometry (PG Instruments, T60/Leicestershire, England) was used as described in detail by Şahin and Samli (2013) (20). Results were given as gallic acid equivalence per gram of dried leaf (mg GAE/g $D L)$.

\section{HPLC}

Extracts obtained under optimum conditions by each solvent system were also analyzed by High Performance Liquid Chromatography (HPLC). The gradient elution program used in this method is shown in Table 1.

Table 1. Gradient program and analysis conditions applied in HPLC.

\begin{tabular}{lccc}
\hline \multicolumn{1}{c}{ Conditions } & \multicolumn{3}{c}{ Program } \\
\hline Agilent 1260 (Agilent, Waldbronn, ABD) (model) & Time (sec) & A (\%) & B (\%) \\
\cline { 2 - 4 } Agilent Eclipse Plus C18 RRHD 18 (3 mm x 5 mm; & 0.0 & 100 & 0 \\
$1,8 \mu \mathrm{m})$ (column) & & 100 & 0 \\
Mobile phase A: Water + 0.1\% formic acid (v/v) & 0.5 & & \\
Mobile phase B: Acetonitrile + 0.1\% formic acid & & 60 & 40 \\
(v/v) & 7.0 & 0 & 100 \\
$276 \mathrm{~nm}$ (wavelength) & 7.1 & 0 & 100 \\
$1 \mathrm{~mL} /$ min (flow rate) & 8.6 & 100 & 0 \\
$40^{\circ} \mathrm{C}$ (column temperature) & 8.7 & & \\
$20 \mu \mathrm{L}$ (injection volume) & & & \\
\hline
\end{tabular}




\section{Kinetics of UAE}

Kinetic description of olive leaf extraction by means of UAE was held by second-order kinetic model as stated below (Qu et al., 2010):

$$
\frac{d C_{t}}{d t}=k\left(C_{e}-C_{t}\right)^{2}
$$

The linearized form of the equation 1 is stated as given below:

$$
\frac{t}{C_{t}}=\frac{1}{k C_{e}^{2}}+\frac{t}{C_{e}}
$$

where: $(\mathrm{mg} / \mathrm{g})$

$\mathrm{C}_{\mathrm{t}}=$ Concentration of TPC at time $t$

$\mathrm{C}_{\mathrm{e}}=$ Concentration of TPC when the equilibrium is attained $(\mathrm{mg} / \mathrm{g})$

$\mathrm{t}=$ Extraction time $(\mathrm{min})$

$\mathrm{k}=$ Rate constant $(\mathrm{g} / \mathrm{mg} \cdot \mathrm{min})$

When $t$ approaches to 0 , initial extraction rate can be expressed as $h$ $(\mathrm{mg} / \mathrm{g} \cdot \mathrm{min})$ :

$$
h=k C_{e}^{2}
$$

If $h$ is substituted into Eq. $2, C_{t}$ can be stated as follows:

$$
C_{t}=\frac{t}{(1 / h)+\left(t / C_{e}\right)}
$$

\section{Statistical analysis}

Analysis of variance (ANOVA) statistical test was utilized through Tukey's test of InStat $\mathbb{R}$ software (GraphPad, San Diego, CA, USA) to analyze the means of three replicate outputs.

Reliability of the mathematical model was evaluated by some indicators such as correlation coefficient $\left(R^{2} / r^{2}\right)$ and the rootmean-square deviations ( $r m s d)$ :

$$
r m s d=\sqrt{\frac{\sum_{i=1}^{n}\left(C_{i, \exp }-C_{i, c a l}\right)^{2}}{n}}
$$

$\mathrm{n}=$ number of the experiments

$\mathrm{C}_{\mathrm{i}, \text { exp }}=$ concentration value of experiment $i$

$\mathrm{C}_{\mathrm{i}, \text { cal }}=$ calculated concentration value of the $i$

\section{RESULTS AND DISCUSSIONS}

\section{Effect of the type of solvent}

Table 2 indicates the influence of solvent type under several temperature values on the

\begin{tabular}{|c|c|c|c|c|}
\hline $\begin{array}{l}\text { Solvent } \\
(v / v)\end{array}$ & $\begin{array}{c}\mathrm{T} \\
\left({ }^{\circ} \mathrm{C}\right)\end{array}$ & $\begin{array}{c}\text { Time } \\
\text { (minute) }\end{array}$ & $\begin{array}{l}\text { Extract yield* } \\
(\mathrm{mg} / \mathrm{g} \mathrm{DL})\end{array}$ & $\begin{array}{c}\text { TPC }^{* *} \\
\text { (mg GAE/g DL) }\end{array}$ \\
\hline \multirow{15}{*}{$50 \% \mathrm{EtOH}$} & \multirow{5}{*}{30} & 20 & $194.74 \pm 6.50$ & $20.78 \pm 0.45$ \\
\hline & & 30 & $202.55 \pm 9.01$ & $24.56 \pm 1.20$ \\
\hline & & 40 & $255.00 \pm 9.81$ & $25.18 \pm 1.68$ \\
\hline & & 50 & $254.98 \pm 8.25$ & $27.11 \pm 1.88$ \\
\hline & & 60 & $263.06 \pm 7.51$ & $28.71 \pm 2.39$ \\
\hline & \multirow{5}{*}{40} & 20 & $202.24 \pm 9.82$ & $28.78 \pm 1.29$ \\
\hline & & 30 & $220.01 \pm 8.41$ & $31.09 \pm 1.45$ \\
\hline & & 40 & $257.60 \pm 5.21$ & $31.54 \pm 2.00$ \\
\hline & & 50 & $270.71 \pm 5.60$ & $32.53 \pm 2.40$ \\
\hline & & 60 & $281.20 \pm 6.74$ & $32.84 \pm 1.11$ \\
\hline & \multirow{5}{*}{50} & 20 & $277.57 \pm 7.71$ & $32.43 \pm 1.11$ \\
\hline & & 30 & $298.09 \pm 6.45$ & $34.50 \pm 3.32$ \\
\hline & & 40 & $301.79 \pm 9.46$ & $36.80 \pm 1.45$ \\
\hline & & 50 & $320.91 \pm 7.55$ & $37.33 \pm 3.01$ \\
\hline & & 60 & $322.33 \pm 7.01$ & $37.38 \pm 1.75$ \\
\hline $50 \% \mathrm{MeOH}$ & 30 & 20 & $172.44 \pm 5.12$ & $26.18 \pm 1.38$ \\
\hline
\end{tabular}
extract yield and TPC of each olive leaf extract obtained by UAE as a function of time.

Table 2. Change of the extract yield and TPC of the olive leaf extracts as a function of time with various solvent types under different temperatures. 


\begin{tabular}{|c|c|c|c|c|}
\hline $\begin{array}{l}\text { Solvent } \\
(v / v)\end{array}$ & $\begin{array}{c}\mathrm{T} \\
\left({ }^{\circ} \mathrm{C}\right)\end{array}$ & $\begin{array}{c}\text { Time } \\
\text { (minute) }\end{array}$ & $\begin{array}{l}\text { Extract yield* } \\
\text { (mg/g DL) }\end{array}$ & $\begin{array}{c}\text { TPC }^{* *} \\
\text { (mg GAE/g DL) }\end{array}$ \\
\hline & & 30 & $201.98 \pm 6.66$ & $28.70 \pm 0.58$ \\
\hline & & 40 & $233.03 \pm 8.45$ & $31.03 \pm 0.28$ \\
\hline & & 50 & $234.09 \pm 9.01$ & $33.28 \pm 0.70$ \\
\hline & & 60 & $234.48 \pm 5.01$ & $35.20 \pm 1.96$ \\
\hline & & 20 & $188.14 \pm 4.21$ & $38.55 \pm 1.65$ \\
\hline & & 30 & $229.89 \pm 8.02$ & $40.30 \pm 2.29$ \\
\hline & 40 & 40 & $255.98 \pm 9.78$ & $42.72 \pm 3.25$ \\
\hline & & 50 & $277.31 \pm 9.90$ & $43.40 \pm 1.28$ \\
\hline & & 60 & $279.07 \pm 4.00$ & $43.87 \pm 3.04$ \\
\hline & & 20 & $242.04 \pm 6.12$ & $44.11 \pm 1.76$ \\
\hline & & 30 & $257.57 \pm 4.30$ & $46.97 \pm 2.06$ \\
\hline & 50 & 40 & $288.99 \pm 6.13$ & $49.22 \pm 2.48$ \\
\hline & & 50 & $303.88 \pm 7.13$ & $51.01 \pm 2.85$ \\
\hline & & 60 & $310.26 \pm 7.50$ & $51.78 \pm 3.03$ \\
\hline \multirow{15}{*}{$100 \%$ EtOH } & \multirow{5}{*}{30} & 20 & $81.89 \pm 3.51$ & $9.79 \pm 0.5$ \\
\hline & & 30 & $100.91 \pm 5.06$ & $10.99 \pm 1.75$ \\
\hline & & 40 & $124.07 \pm 4.45$ & $12.00 \pm 2.03$ \\
\hline & & 50 & $130.21 \pm 5.55$ & $13.60 \pm 2.32$ \\
\hline & & 60 & $132.89 \pm 4.44$ & $15.15 \pm 1.00$ \\
\hline & \multirow{5}{*}{40} & 20 & $127.56 \pm 5.50$ & $16.24 \pm 1.5$ \\
\hline & & 30 & $131.87 \pm 4.12$ & $18.09 \pm 2.89$ \\
\hline & & 40 & $134.65 \pm 6.77$ & $18.97 \pm 3.01$ \\
\hline & & 50 & $145.00 \pm 4.99$ & $20.06 \pm 2.21$ \\
\hline & & 60 & $147.53 \pm 5.33$ & $20.28 \pm 1.51$ \\
\hline & \multirow{5}{*}{50} & 20 & $160.72 \pm 7.50$ & $20.99 \pm 2.50$ \\
\hline & & 30 & $172.90 \pm 4.54$ & $23.25 \pm 1.78$ \\
\hline & & 40 & $172.87 \pm 4.33$ & $23.57 \pm 2.75$ \\
\hline & & 50 & $173.00 \pm 7.10$ & $24.14 \pm 2.75$ \\
\hline & & 60 & $176.42 \pm 7.44$ & $24.46 \pm 2.02$ \\
\hline \multirow{15}{*}{$100 \% \mathrm{MeOH}$} & \multirow{5}{*}{30} & 20 & $171.89 \pm 5.09$ & $26.53 \pm 3.02$ \\
\hline & & 30 & $188.45 \pm 6.06$ & $27.91 \pm 3.30$ \\
\hline & & 40 & $199.96 \pm 7.06$ & $30.00 \pm 1.45$ \\
\hline & & 50 & $255.98 \pm 6.77$ & $30.71 \pm 2.06$ \\
\hline & & 60 & $266.89 \pm 6.50$ & $31.42 \pm 1.50$ \\
\hline & \multirow{5}{*}{40} & 20 & $196.88 \pm 3.64$ & $30.87 \pm 3.02$ \\
\hline & & 30 & $242.22 \pm 7.79$ & $33.01 \pm 3.12$ \\
\hline & & 40 & $254.61 \pm 7.03$ & $36.45 \pm 2.85$ \\
\hline & & 50 & $274.59 \pm 6.84$ & $38.40 \pm 1.98$ \\
\hline & & 60 & $284.04 \pm 5.51$ & $39.89 \pm 3.00$ \\
\hline & \multirow{5}{*}{50} & 20 & $252.44 \pm 6.16$ & $38.49 \pm 3.00$ \\
\hline & & 30 & $277.65 \pm 7.67$ & $41.70 \pm 2.45$ \\
\hline & & 40 & $296.64 \pm 4.55$ & $42.36 \pm 1.99$ \\
\hline & & 50 & $312.98 \pm 5.78$ & $42.96 \pm 2.07$ \\
\hline & & 60 & $328.82 \pm 7.02$ & $43.07 \pm 3.50$ \\
\hline \multirow[t]{6}{*}{ Water } & \multirow{5}{*}{30} & 20 & $178.65 \pm 4.79$ & $12.30 \pm 2.50$ \\
\hline & & 30 & $187.98 \pm 8.03$ & $14.18 \pm 1.88$ \\
\hline & & 40 & $192.87 \pm 7.16$ & $14.95 \pm 2.78$ \\
\hline & & 50 & $200.00 \pm 8.01$ & $16.01 \pm 3.14$ \\
\hline & & 60 & $207.15 \pm 4.00$ & $17.24 \pm 2.50$ \\
\hline & 40 & 20 & $201.34 \pm 7.77$ & $16.99 \pm 1.78$ \\
\hline
\end{tabular}




\begin{tabular}{|c|c|c|c|c|}
\hline $\begin{array}{c}\text { Solvent } \\
(v / v)\end{array}$ & $\begin{array}{c}\mathrm{T} \\
\left({ }^{\circ} \mathrm{C}\right)\end{array}$ & $\begin{array}{c}\text { Time } \\
\text { (minute) }\end{array}$ & $\begin{array}{c}\text { Extract yield* } \\
\text { (mg/g DL) }\end{array}$ & $\begin{array}{c}\operatorname{TPC}^{* *} \\
\text { (mg GAE/g DL) }\end{array}$ \\
\hline & & 30 & $206.23 \pm 8.30$ & $18.91 \pm 3.05$ \\
\hline & & 40 & $211.09 \pm 4.73$ & $21.25 \pm 1.89$ \\
\hline & & 50 & $218.78 \pm 5.79$ & $22.01 \pm 2.01$ \\
\hline & & 60 & $217.04 \pm 6.00$ & $22.84 \pm 2.06$ \\
\hline & \multirow{5}{*}{50} & 20 & $200.89 \pm 5.44$ & $18.70 \pm 1.50$ \\
\hline & & 30 & $207.56 \pm 6.78$ & $20.95 \pm 0.98$ \\
\hline & & 40 & $212.37 \pm 6.00$ & $22.87 \pm 0.88$ \\
\hline & & 50 & $218.83 \pm 7.11$ & $24.24 \pm 1.08$ \\
\hline & & 60 & $220.13 \pm 4.51$ & $26.40 \pm 2.01$ \\
\hline & \multirow{5}{*}{60} & 20 & $209.35 \pm 6.88$ & $19.24 \pm 2.35$ \\
\hline & & 30 & $216.38 \pm 6.44$ & $22.24 \pm 2.08$ \\
\hline & & 40 & $228.26 \pm 6.51$ & $25.07 \pm 2.11$ \\
\hline & & 50 & $234.92 \pm 6.42$ & $28.01 \pm 2.71$ \\
\hline & & 60 & $246.40 \pm 6.00$ & $30.67 \pm 3.10$ \\
\hline & \multirow{5}{*}{70} & 20 & $226.73 \pm 4.89$ & $21.14 \pm 1.33$ \\
\hline & & 30 & $240.57 \pm 5.00$ & $23.02 \pm 1.77$ \\
\hline & & 40 & $252.34 \pm 3.01$ & $25.46 \pm 1.48$ \\
\hline & & 50 & $255.91 \pm 5.78$ & $25.65 \pm 1.86$ \\
\hline & & 60 & $254.86 \pm 6.11$ & $25.75 \pm 2.50$ \\
\hline & \multirow{5}{*}{80} & 20 & $226.59 \pm 7.77$ & $22.32 \pm 2.03$ \\
\hline & & 30 & $236.71 \pm 5.78$ & $23.46 \pm 3.01$ \\
\hline & & 40 & $255.12 \pm 7.99$ & $25.19 \pm 2.14$ \\
\hline & & 50 & $254.98 \pm 8.78$ & $25.86 \pm 1.13$ \\
\hline & & 60 & $257.91 \pm 9.00$ & $25.96 \pm 3.00$ \\
\hline
\end{tabular}

Both extract yield and TPC in all solvent increases the polarity of $\mathrm{MeOH}$-water mixture systems rose steadily with time. Generally, (22).

after 40 minutes, the slow extraction was found out by a low rise in the yields. Hence, 60 minute is accepted as the equilibrium time in the relevant process (Table 2 ). EtOH gave the poorest extract yield, whereas $\mathrm{MeOH}$ showed the greatest performance. Water did not produce the highest yields, even though it is the most polar one among the selected solvents. This might be a matter of mass transfer, where water's comparatively higher viscosity leads to lower yields. On the other hand, the $50 \% \mathrm{MeOH}$ treatment showed the highest yield of TPC, due to the fact that addition of water into the solvent gives rise to open the pores in the plant matrix by increasing the diffusion of the phenolics into the solvent. On the other hand, $\mathrm{MeOH}$ itself also assists for disruption of the targeted ingredients from the plant material $(15,21)$. Additionally, water's high dielectric constant also might be the another reason since that

\section{Effect of temperature}

Figure 2 represents the effect of temperature on the extract yield and TPC of each olive leaf extract obtained by UAE through various solvents. More precisely, the figure exhibits the comparative extract yield and TPC of extractions at the $60^{\text {th }}$ minute (at equilibrium), respectively. Both extract yield and TPC of all solvents increased by temperature. Rather, the same trend was observed for each solvent with respect to both extract yield and TPC. However, for water, the TPC of the extracts started to decrease after a certain temperature point $\left(60^{\circ} \mathrm{C}\right)$ and reached the equilibrium at $70{ }^{\circ} \mathrm{C}$. This might be explained by degradation owing to the hydrolysis and oxidation of the antioxidant ingredients (23). This might be ascribed to the enzyme polyphenol oxidase, which degrade polyphenols in water extracts, whereas they are not active in alcohol medium. On the 
other hand, consuming much longer unreasonable condition with respect to temperature is also obvious to be an economical points.
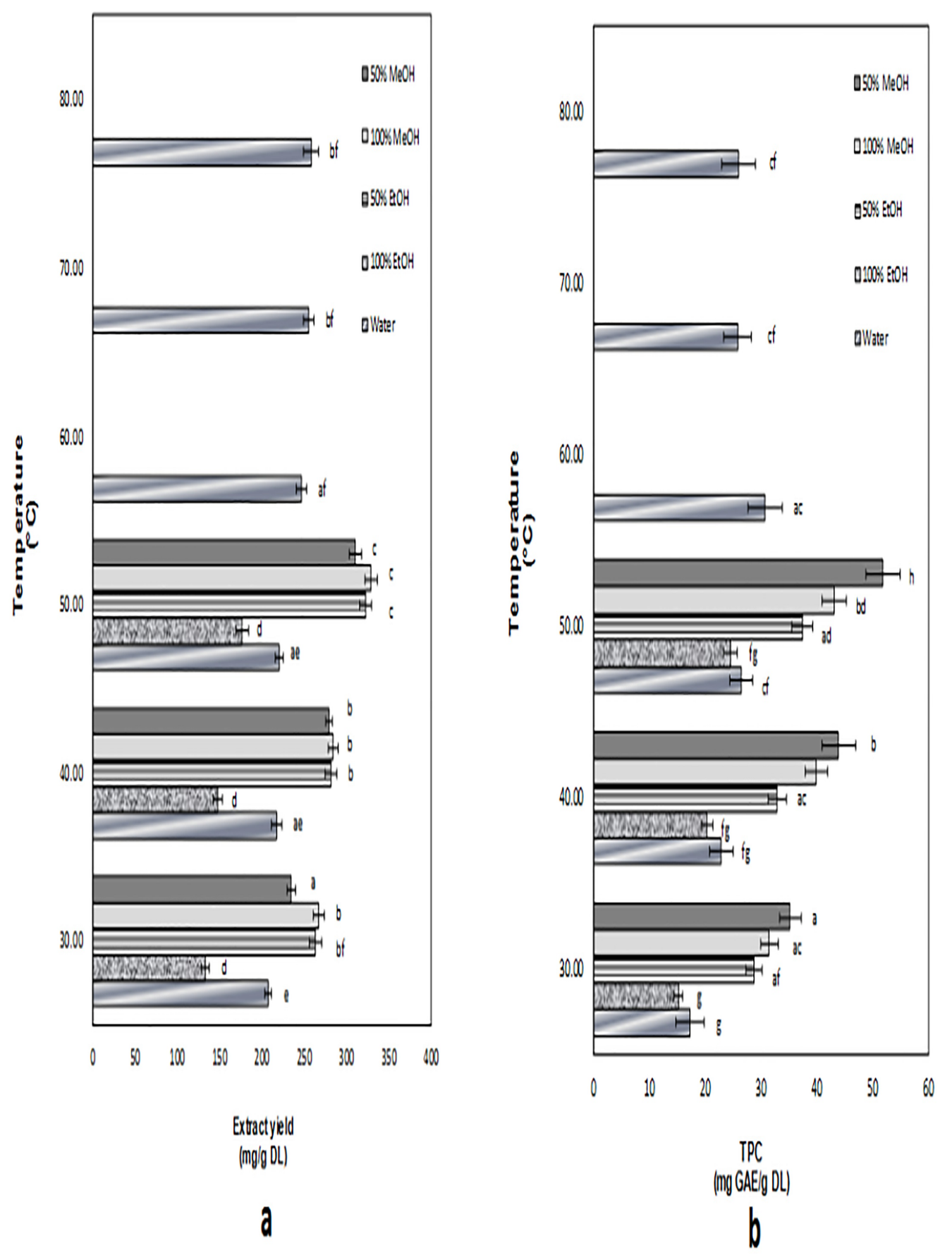

Figure 2. Effect of temperature on the extract amount (a) and TPC (b) depending on the solvent type. Data are expressed as the mean $(n=3) \pm S$.D. Values for each column not sharing a common letter were significantly different from each cultivar at $P<0.05$. 
The extracts obtained by $50 \% \mathrm{MeOH}$ and $\mathrm{EtOH}$ solutions and pure $\mathrm{MeOH}$ at $50{ }^{\circ} \mathrm{C}$ shared the highest yield with the values of $310.26,322.33$ and $328.82 \mathrm{mg} / \mathrm{g} \mathrm{DL}$, which are not significantly different at $P>0.05$ (Figure $2 \mathrm{a}$ ). On the other hand, the $50 \% \mathrm{EtOH}$ extracts at 30,40 and $50{ }^{\circ} \mathrm{C}$ gave the statistically the same poorest yields (at $P>0.05$ ). The maximum TPC was extracted by $50 \% \mathrm{MeOH}$ solution at $50^{\circ} \mathrm{C}$ with the quantity of $51.78 \mathrm{mg} \mathrm{GAE} / \mathrm{g} \mathrm{DL}$ (Figure 2b). As seen in the same figure, there was no significant difference $(P>0.05)$ between the lowest values of TPC obtained by pure EtOH and water at 30,40 and $50^{\circ} \mathrm{C}$.

\section{Kinetic study of the extraction process}

Table 3 presents the initial extraction rate $(h)$, the equilibrium concentration $\left(C_{e}\right)$, the second-order extraction rate constant $(k)$ and the correlation coefficient $\left(R^{2}\right)$, which were calculated from the slopes plotted by $t / C_{t}$ against $t$ (Eq.2). The second-order kinetic model equation was used to calculate the predictive values of TPC under the concerned experimental conditions. The relationship between the actual findings and the calculated results of the kinetic model for different conditions are also shown with the correlation coefficient $\left(r^{2}\right)$ and root-mean-square deviation $(r m s d)$ in Table 3.

Generally, the kinetic parameters of the UAE of olive leaf polyphenols increased with temperature as expected. The kinetic values were found higher for the pure $\mathrm{MeOH}$ extracts, which are consistent with the results of the related experiments. The values of correlation coefficients obtained with the kinetic model were extremely high $\left(R^{2}=\right.$ 0.9555-0.9994) for each UAE experiment with different solvents under several temperature values. Consequently, second-order kinetic equation has been found to be convenient to describe the kinetics of UAE of olive leaves.

Depending on the high correlation coefficient $\left(r^{2}=0.9332-0.9930\right)$ and the low root mean squared deviation $(r m s d=0.1229-1.7875)$ in all the experiments, the second-order kinetic model used in this study shows to be an appropriate model for the relevant system.

Table 3. Values for $h, k, C_{e}$ and $R^{2}$ of the second-order kinetic model of UAE through various solvent types under different temperatures. $r^{2}$ and $r m s d$ of the experimentally obtained values of the TPC versus the calculated values using the kinetic model for each condition of extraction.

\begin{tabular}{|c|c|c|c|c|c|c|c|}
\hline \multirow[b]{2}{*}{$\begin{array}{c}\text { Solvent } \\
(v / v)\end{array}$} & \multirow[b]{2}{*}{$\begin{array}{c}\mathrm{T} \\
\left({ }^{\circ} \mathrm{C}\right) \\
\end{array}$} & \multirow[b]{2}{*}{$\begin{array}{c}h \\
(\mathrm{mg} / \mathrm{g} \cdot \mathrm{min})\end{array}$} & \multirow[b]{2}{*}{$\begin{array}{c}\mathbf{k} \\
(\mathrm{g} / \mathrm{mg} \cdot \mathrm{min})\end{array}$} & \multirow[b]{2}{*}{$\begin{array}{c}C_{e} \\
(\mathrm{mg} / \mathrm{g}) \\
\end{array}$} & \multirow[b]{2}{*}{$\mathbf{R}^{2}$} & \multicolumn{2}{|c|}{$\begin{array}{c}\text { Relationship } \\
\text { between the } \\
\text { experimental and } \\
\text { calculated data }\end{array}$} \\
\hline & & & & & & rmsd & $r^{2}$ \\
\hline \multirow{3}{*}{$50 \% \mathrm{EtOH}$} & 30 & 2.56 & 0.0021 & 34.72 & 0.9949 & 0.5286 & 0.9332 \\
\hline & 40 & 8.08 & 0.0065 & 35.21 & 0.9992 & 0.1229 & 0.9930 \\
\hline & 50 & 8.01 & 0.0048 & 40.82 & 0.9989 & 0.2592 & 0.9607 \\
\hline \multirow{3}{*}{$50 \% \mathrm{MeOH}$} & 30 & 3.07 & 0.0017 & 42.74 & 0.9953 & 0.6213 & 0.9672 \\
\hline & 40 & 10.38 & 0.0047 & 46.95 & 0.9987 & 0.6982 & 0.9718 \\
\hline & 50 & 8.07 & 0.0028 & 57.14 & 0.9997 & 0.8745 & 0.9894 \\
\hline \multirow{3}{*}{$100 \% \mathrm{EtOH}$} & 30 & 0.77 & 0.0017 & 21.37 & 0.9555 & 0.4874 & 0.9678 \\
\hline & 40 & 2.67 & 0.0049 & 23.31 & 0.9994 & 0.6347 & 0.9824 \\
\hline & 50 & 5.64 & 0.0081 & 26.39 & 0.9992 & 0.3645 & 0.9674 \\
\hline \multirow{3}{*}{$\begin{array}{l}100 \% \\
\mathrm{MeOH}\end{array}$} & 30 & 5.16 & 0.0043 & 34.84 & 0.9992 & 0.4093 & 0.9692 \\
\hline & 40 & 4.00 & 0.0018 & 47.39 & 0.9969 & 0.7845 & 0.9633 \\
\hline & 50 & 13.99 & 0.0067 & 45.66 & 0.9995 & 1.7875 & 0.9581 \\
\hline
\end{tabular}


Şahin S. JOTCSA. 2019; 6(3): 383-394.

RESEARCH ARTICLE

\begin{tabular}{llllllll}
\hline \multirow{6}{*}{ Water } & 30 & 1.39 & 0.0031 & 21.19 & 0.9941 & 0.2859 & 0.9730 \\
& 40 & 2.11 & 0.0027 & 27.86 & 0.9983 & 0.2571 & 0.9859 \\
& 50 & 1.99 & 0.0018 & 32.89 & 0.9920 & 1.1361 & 0.9540 \\
& 60 & 1.57 & 0.0008 & 44.05 & 0.9845 & 0.6680 & 0.9741 \\
& 70 & 3.93 & 0.0046 & 29.33 & 0.9966 & 1.6563 & 0.9505 \\
& 80 & 4.83 & 0.0059 & 28.65 & 0.9989 & 0.5339 & 0.9632 \\
\hline
\end{tabular}

Major polyphenol of the extract

As seen in Figure 3, oleuropein remarkably surpasses of all phenolic compounds in olive leaf extract. Oleuropein has been verified to be the major polyphenolic compound of olive leaf. Many pharmacological effects of olive leaf are also attributed to this component (7).

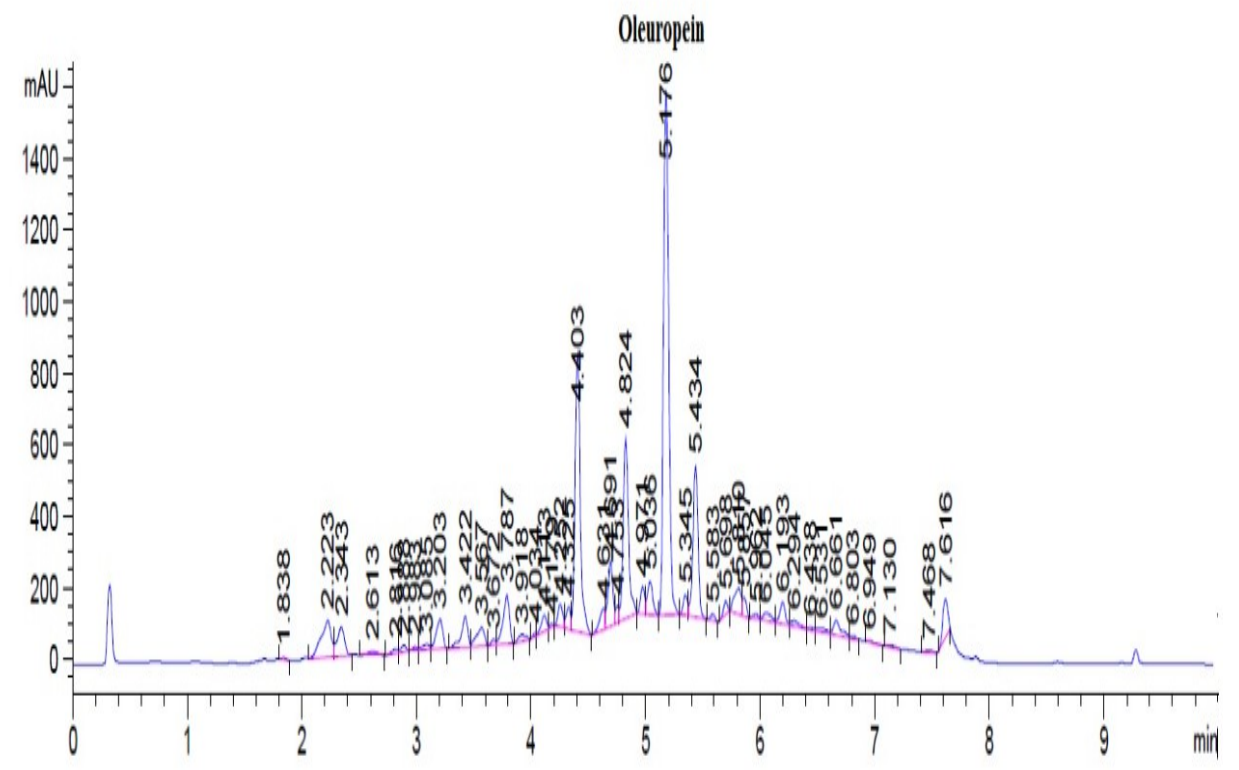

Figure 3. HPLC chromatogram of olive leaf extract obtained under optimum extraction conditions by means of $50 \%(\mathrm{v} / \mathrm{v})$ methanol.

Figure 4 demonstrates the oleuropein It was found to be between 8.69 and $31 \mathrm{mg}$ contents of olive leaf extracts obtained under per gram of dried leaf. This output is optimum conditions by each solvent system. consistent with the reported results (24). 


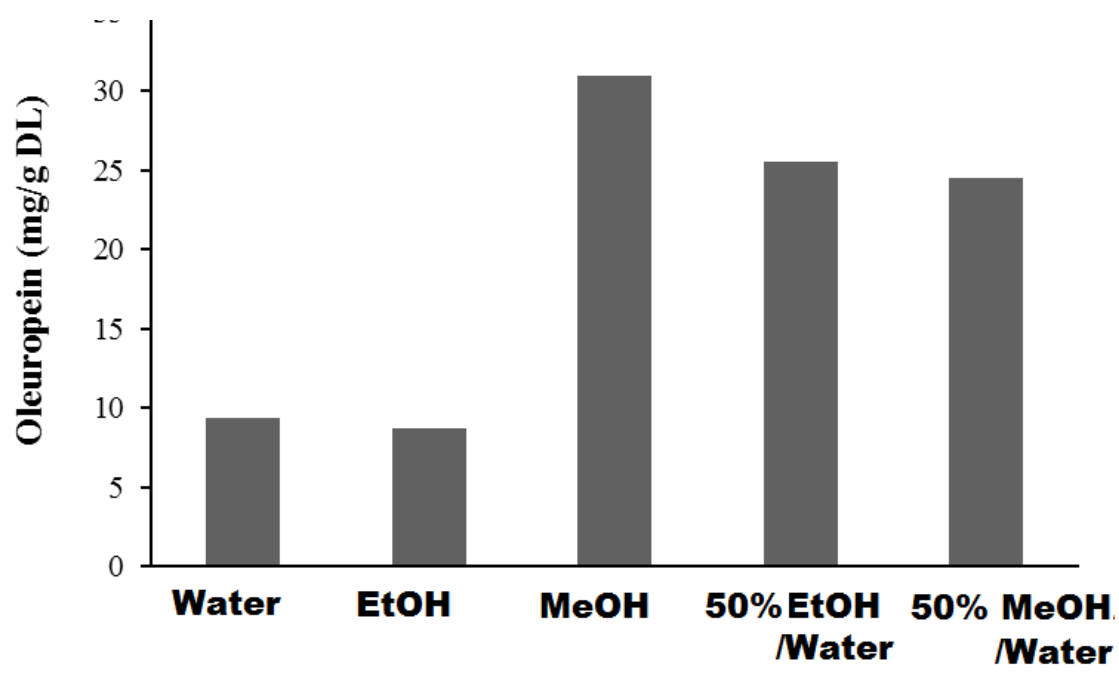

Figure 4. Oleuropein quantity of olive leaf extracts depending on the solvent.

\section{CONCLUSION}

Addition of water to alcohol improved the extraction of bioactive ingredients. TPC from water extracts decreased after a certain temperature point, as a result of degradation problems. Second-order kinetic equation has been found to be adequate to represent the experimental outcome for the ultrasoundassisted extraction of biologically active ingredients from olive leaves.

\section{REFERENCES}

1. Brahmi F, Mechri B, Dhibi M, Hammami M. Variations in phenolic compounds and antiradical scavenging activity of Olea europaea leaves and fruits extracts collected in two different seasons. Industrial Crops and Products. 2013; 49: 256-264.

2. Salido S, Pérez-Bonilla M, Adams RP, Altarejos J. Phenolic Components and Antioxidant Activity of Wood Extracts from 10 Main Spanish Olive Cultivars. Journal of Agricultural and Food Chemistry. 2015; 63: 6493-6500.

3. Talhaoui N, Taamalli A, Gómez-Caravaca AM, Fernández-Gutiérrez A, Segura-Carretero A. Phenolic compounds in olive leaves: Analytical determination, biotic and abiotic influence, and health benefits. Food Research Interntional. 2015; 77: 92-108.

4. Elhussein EAA, Şahin S. Drying behaviour, effective diffusivity and energy of activation of olive leaves dried by microwave, vacuum and oven drying methods. Heat and Mass Transfer. 2018; 54: 1901-1911.

5. Şahin S, Samli R, Tan ASB, Barba FJ, Chemat F, Cravotto G, Lorenzo JM. SolventFree Microwave-Assisted Extraction of Polyphenols from Olive Tree Leaves: Antioxidant and Antimicrobial Properties. Molecules. 2017; 22: 1056.

6. Bouaziz M, Sayadi S. Isolation and evaluation of antioxidants from leaves of a Tunisian cultivar olive tree. European Journal of Lipid Science and Technology. 2005; 107: 497-504.

7. Şahin S, Bilgin M. Olive tree (Olea europaea L.) leaf as a waste by-product of table olive and olive oil industry: a review. Journal of the Science of Food and Agriculture. 2018; 98: 1271-1279.

9. Şahin S, Elhussein E, Bilgin M, Lorenzo JM, Barba FJ, Roohinejad S. Effect of drying method on oleuropein, total phenolic content, flavonoid content, and antioxidant activity of olive ( Olea europaea ) leaf. Journal of Food Processing and Preservation. 2018; 42: e13604.

10. Şahin S, Sayım E, Bilgin M. Effect of olive leaf extract rich in oleuropein on the quality of virgin olive oil. Journal of Food Science and Technology. 2017; 54: 1721-1728. 
11. Bilgin $M$, Şahin S. Effects of geographical origin and extraction methods on total phenolic yield of olive tree (Olea europaea) leaves. Journal of the Taiwan Instute of Chemical Engineers. 2013; 44: 8-12.

12. Soria AC, Villamiel M. Effect of ultrasound on the technological properties and bioactivity of food: a review. Trends in Food Science and Technology. 2010; 21: 323-331.

13. Novak I, Janeiro $P$, Seruga M, OliveiraBrett AM. Ultrasound extracted flavonoids from four varieties of Portuguese red grape skins determined by reverse-phase highperformance liquid chromatography with electrochemical detection. Analaytica Chimica Acta. 2008; 630: 107-115.

14. Joana Gil-Chávez G, Villa JA, Fernando Ayala-Zavala J, Basilio Heredia J, Sepulveda D, Yahia EM, González-Aguilar GA.

Technologies for Extraction and Production of Bioactive Compounds to be Used as Nutraceuticals and Food Ingredients: An Overview. Comprehensive Reviews in Food Science and Food Safety. 2013; 12: 5-23.

15. Wang $L$, Weller CL. Recent advances in extraction of nutra- ceuticals from plants. Trends in Food Science and Technology. 2006; 17: 300-312.

16. Esclapez MD, García-Pérez JV, Mulet A, Cárcel JA. Ultrasound-Assisted Extraction of Natural Products. Food Engineering Reviews. 2011; 3: 108-120.

17. Leighton TG. What is ultrasound? Progress in biophysics and molecular biology. 2007; 93: 3-83.
18. Şahin S, Saeed N, Malik A, Perez JL, Brockington JE. Seasonal Changes of Individual Phenolic Compounds in Leaves of Twenty Olive Cultivars Grown in Texas. Journal of Agricultural Science and Technology B. 2012; 2: 242-247.

19. Malik NSA, Bradford JM. Changes in oleuropein levels during differentiation and development of floral buds in "Arbequina" olives. Scientia Horticulturae. 2006; 110: 274-278.

20. Şahin S, Şaml R. Optimization of olive leaf extract obtained by ultrasound-assisted extraction with response surface methodology. Ultrasonic Sonochemistry. 2013; 20: 595-602.

21. Lang Q, Wai CM. Supercritical fluid extraction in herbal and natural product studies - a practical review. Talanta, 2001; 53: 771-782.

22. Spigno G, De Faveri DM. Microwaveassisted extraction of tea phenols: $A$ phenomenological study. Journal of Food Engineering. 2009; 93: 210-217.

23. Co M, Zettersten C, Nyholm L, Sjöberg PJR, Turner C. Degradation effects in the extraction of antioxidants from birch bark using water at elevated temperature and pressure. Analytica Chimica Acta. 2012; 716: 40-48.

24. Alañón $M E$, Ivanović $M$, Gómez-Caravaca AM, Arráez-Román D, Segura-Carretero A. Choline chloride derivative-based deep eutectic liquids as novel green alternative solvents for extraction of phenolic compounds from olive leaf. Arabian Journal of Chemistry. 2018; in press, doi:10.1016/J.ARABJC.2018.01.003. 
Şahin S. JOTCSA. 2019; 6(3): 383-394.

RESEARCH ARTICLE 